\title{
Azygos continuation of interrupted inferior vena cava in association with sick sinus syndrome
}

\author{
R Vijayvergiya, M N Bhat, R M Kumar, S G Vivekanand, A Grover
}

Heart 2005;91:e26 (http://www.heartjnl.com/cgi/content/full/91/4/e26). doi: 10.1136/hrt.2004.049866

\begin{abstract}
Various diagnostic and therapeutic procedures of the right side of the heart and the systemic venous system have increased the need for ready access to the inferior vena cava (IVC) through the transfemoral route. Anatomical variations or obstruction of the IVC can make these procedures difficult. The case of 47 year old woman with an interrupted infrahepatic IVC with azygos continuation accompanied by sick sinus syndrome and a structurally normal heart is reported. Negotiating a temporary pacing lead from the IVC to the right atrium was difficult. Ultimately, the lead took the course from the IVC to azygos vein to superior vena cava to right atrium to right ventricular apex. Permanent $\mathrm{VVI}$ pacing through the right subclavian route was uneventful, as the superior vena cava and its tributaries had a normal course. An awareness of the existence of these anomalies before pacing can lead to the use of an alternative route for pacing, which may avoid undue delay of an otherwise urgently needed procedure.
\end{abstract}

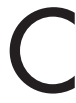
ongenital absence of the hepatic segment of the inferior vena cava (IVC) is a well recognised but uncommon anatomical variant. It is commonly associated with other congenital heart disease but isolated occurrence without heart disease may go unnoticed during early life and may be incidentally detected during radiological examination or vascular interventions. Here, we report a case of sick sinus syndrome in a patient in whom the anomaly was detected incidentally during temporary pacing through the trans-

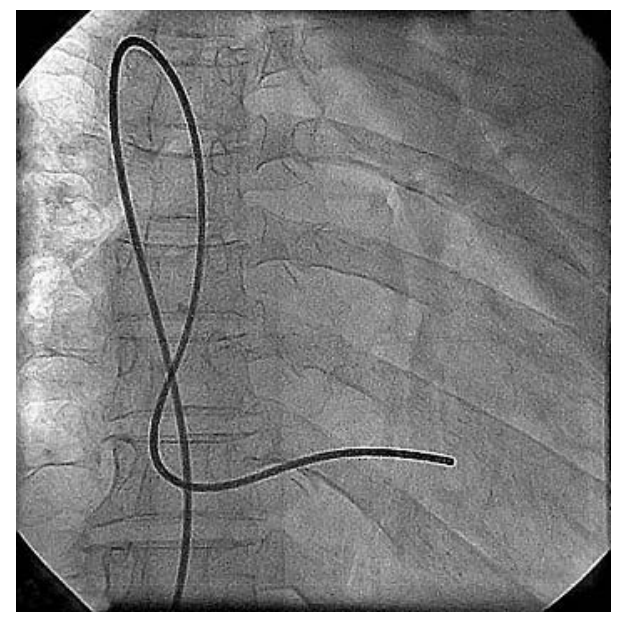

Figure 1 Radiograph showing a temporary pacing lead at the right ventricular apex with an unusual loop because of an interrupted inferior vena cava (IVC). femoral route. The angiographic features and clinical importance of this condition are discussed.

\section{CASE REPORT}

A 47 year old woman was admitted in September 2003 with a history of recurrent syncopal attacks of one week's duration. Clinical examination found a regular pulse rate of 38 beats/ min of normal volume and character, and blood pressure 110/ $80 \mathrm{~mm} \mathrm{Hg}$. Cardiovascular and other systemic examinations were unremarkable. ECG showed an absence of the P wave and slow junctional rhythm. She was admitted for transfemoral temporary pacing under fluoroscopic guidance in the emergency department. The pacing lead was introduced through the right femoral vein. The lead could not be negotiated from the IVC to the right atrium. On manipulation, the lead had a course from the IVC to the superior vena cava to the right atrium and then the right ventricular apex (fig 1). Successful temporary pacing was achieved. Thereafter, echocardiography showed situs solitus and no structural heart disease. On the next day, venography showed total interruption of a single right sided IVC below the hepatic veins. The IVC continued as a dilated right sided azygos vein, which was draining into the superior vena cava (figs 2 and 3). The superior vena cava and its tributaries were normal. Hepatic veins were draining directly into the right atrium (fig 4). Permanent pacemaker implantation was successful (VVI mode, Vita 2SSI Model 230) through the right subclavian vein without any difficulty (fig 5). Ultrasound of the abdomen showed polysplenia. The patient was discharged on day 10 of admission. At 10 months of follow up, she was asymptomatic with all paced rhythm.

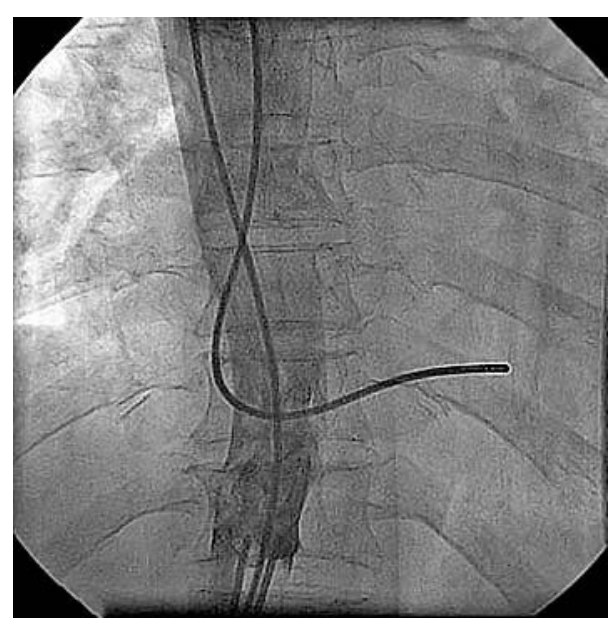

Figure 2 Venogram in the anteroposterior view showing the IVC draining into the superior vena cava. 


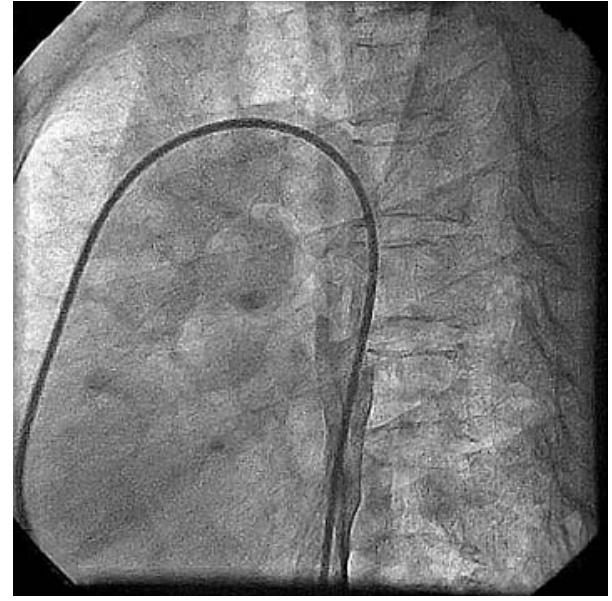

Figure 3 Venogram in the lateral view showing the IVC draining into the superior vena cava.

\section{DISCUSSION}

Infrahepatic IVC interruption with azygos continuation is a rare congenital anomaly especially when it is not associated with congenital heart disease. Its prevalence is $0.6-2.0 \%$ in patients with congenital heart disease and less than $0.3 \%$ among otherwise normal patients. ${ }^{1}$ This developmental anomaly results in termination of the IVC below the hepatic vein. Systemic venous flow beyond this point is accommodated by the dilated azygos and hemiazygos veins, which eventually empty into the superior vena cava through a dilated azygos arch. ${ }^{2}$ During embryogenesis, the IVC is made up of the hepatic, prerenal, renal, and postrenal segments, which by segmental fusion, regression, and midline anastomosis form the IVC. ${ }^{2}$ Failure of the hepatic and prerenal segments to fuse is the most common developmental anomaly of the IVC and results in infrahepatic IVC interruption. The infrahepatic IVC may continue as the azygos vein ${ }^{2-4}$ as in the present index case or may continue as the hemiazygos vein to the left superior vena cava, ${ }^{4}$ intrathoracic veins, ${ }^{5}$ or anomalous intrahepatic veins. ${ }^{6}$ The hepatic segment of the IVC drains directly into the right atrium $^{2}$ as in the index case.

Although most of these isolated anomalies are detected incidentally, they can have clinical implications in certain circumstances. The dilated azygos vein may be misinterpreted as a paracardiac or mediastinal mass on chest radiography. ${ }^{7}$

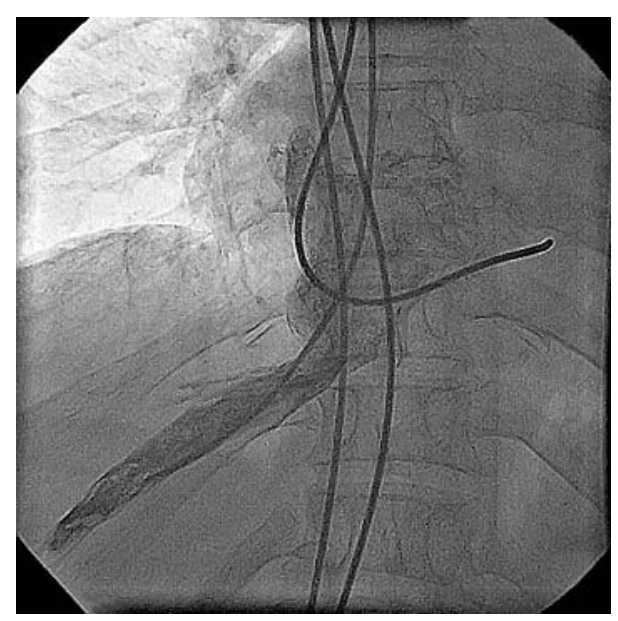

Figure 4 Hepatic veins draining directly into the right atrium.

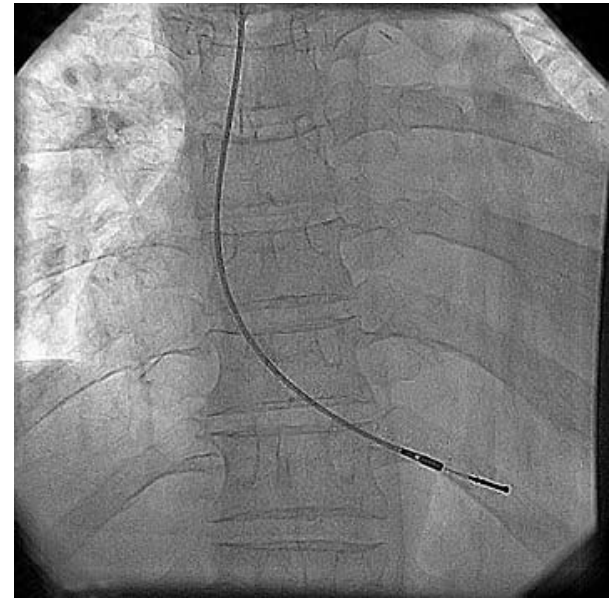

Figure 5 Permanent pacing lead at the right ventricular apex showing the normal course.

The anomaly may be associated with recurrent deep vein thrombosis of the lower $\operatorname{limbs}^{13}$ or with sick sinus syndrome. ${ }^{8}$ There can be procedural difficulties during right heart catheterisation, ${ }^{9}$ electrophysiological studies, ${ }^{10}$ cardiopulmonary bypass surgery, ${ }^{11}$ femoral vein catheter advancement, ${ }^{3}$ IVC filter placement, ${ }^{12}$ and temporary pacing through the transfemoral route (index case). Awareness of the existence of these anomalies before temporary or permanent pacing can help in deciding about following an alternate route for pacing, which may avoid undue delay in an otherwise urgently needed procedure.

We had a problem in inserting the temporary pacing lead and achieving satisfactory pacing parameters through the transfemoral route was delayed because of an unusual reverse " $U$ " loop at the level of the azygos vein to the superior vena cava to the right atrium. This can be critical for a patient who requires temporary pacing in an emergency. Even the routine atrial lead in the right atrial appendage of an otherwise dilated right atrium can repeatedly become dislodged and may require a screw-in atrial lead for permanent atrial pacing in this anomaly. ${ }^{8}$ The recognition of this congenital venous anomaly is important for the cardiologist, especially for conditions such as venous thromboembolism, IVC filter placement, pacing and electrophysiology, cardiopulmonary bypass surgery, and palliative systemic venous-pulmonary artery shunt surgery.

\section{Authors' affiliations}

R Vijayvergiya, M N Bhat, R M Kumar, S G Vivekanand, A Grover, Department of Cardiology, Post Graduate Institute of Medical Education \& Research, Chandigarh, India

Correspondence to: Dr Rajesh Vijayvergiya, Department of Cardiology, PGIMER, Chandigarh-160012, India; rajeshvijay999@hotmail.com

Accepted 1 November 2004

\section{REFERENCES}

1 Timmers GJ, Falke TH, Rauwerda JA, et al. Deep vein thrombosis as a presenting symptom of congenital interruption of the inferior vena cava. Int J Clin Pract 1999;53:75-6.

2 Chuang VP, Mena CE, Hoskins PA. Congenital anomalies of inferior vena cava: review of embryogenesis and presentation of a simplified classification. Br J Radiol 1974;47:206-13

3 Gayer G, Zissin R, Strauss S, et al. IVC anomalies and right renal aplasia detected on CT: a possible link? Abdom Imaging 2003;28:395-9.

4 Roguin N, Lam M, Frenkel A, et al. Radionuclide angiography of azygos continuation of inferior vena cava in left atrial isomerism (polysplenia syndrome). Clin Nucl Med 1987; 12:708-10. 
5 Arakawa A Nagata $Y$, Miyagi S, et al Interruption of inferior vena cava with anomalous continuations. J Comput Tomogr 1987;11:341-5.

6 Balkanci F, Ozmdn MN. Case report: interruption of the inferior vena cava with anomalous intrahepatic continuation. $\mathrm{Br} J$ Radio 1993:66:457-9.

7 Beedie RJ, Yeo W, Morcos SK. Congenital absence of the intrahepatic segment of the inferior vena cava with azygos continuation presenting as a mediastinal mass. Postgrad Med J 1989;65:253-5.

8 Lin KH, Kuo CT, Lin CT. Screw-in atrial lead in a sick sinus syndrome patient with anomalous inferior vena cava. Jpn Heart J $2001 ; 42: 639-44$
9 Ramsaran EK, Filiberti AW, Spodick DH. Isolated anomalous inferior vena cava with azygos drainage. Cardiology 1995;86:257-8.

10 Kler TS, Bhatia A, Saxena A, et al. Catheter ablation of left free wall accessory pathway in a patient with inferior vena cava interruption. Indian Heart $J$ 2002;54:705-7.

11 Wolfhard U, Splittgerber FH, Gocke P, et al. Bilateral inferior vena cava with azygos continuation but without congenital heart disease complicates routine venous cannulation for cardiopulmonary bypass in an adult. Thorac Cardiovasc Surg 1997; 45:40-2.

12 Sardi A, Minken SL. The placement of intracaval filters in an anomalous (leftsided) vena cava. J Vasc Surg 1987;6:84-6. 